Maffulli N, Caine DJ (eds): Epidemiology of Pediatric Sports Injuries: Team Sports.

Med Sport Sci. Basel, Karger, 2005, vol 49, pp 170-191

\title{
Injury Prevention and Future Research
}

\author{
Carolyn A. Emery
}

Sport Medicine Centre, Faculty of Kinesiology, University of Calgary, Calgary, Alta., Canada

\begin{abstract}
Objectives: To critically examine and summarize the literature identifying risk factors and prevention strategies for injury in child and adolescent sport. Data Sources: Seven electronic databases were searched including: Medline, Cumulative Index to Nursing and Allied Health Literature (CINAHL), Psychinfo, Cochrane Database for Systematic and Complete Reviews, Cochrane Controlled Trials Registry, HealthSTAR and SPORTDiscus. Medical subject headings and text words included: athletic injury, sport injury, risk factors, adolescent and child. Additional articles were reviewed based on sport-specific contributions in the previous chapters of this book. Main Results: Despite the diversity of injuries occurring in various pediatric sporting populations, the uniformity with respect to many of the risk factors identified in the literature is noteworthy (i.e. previous injury, age, sport specificity, psychosocial factors, decreased strength and endurance). The literature is significantly limited with respect to the prospective evaluation of risk factors and prevention strategies for injury in pediatric sport. The consistencies, however, between the adult and pediatric literature are encouraging with respect to prevention strategies involving neuromuscular training programs (i.e. balance training programs) to reduce lower extremity injuries in some sports and the use of sport-specific protective equipment (i.e. helmets). Conclusions: Notwithstanding the limitations in the literature, the successful evaluation of some sport-specific prevention strategies to reduce injury in pediatric sport is encouraging. There is significant opportunity to methodologically improve upon the current pediatric sport injury literature in descriptive surveillance research, risk factor evaluation research, and prevention research. There is a need for prospective studies, ideally randomized controlled trials, in the evaluation of prevention strategies in pediatric sport. The integration of basic science, laboratory and epidemiological research is critical in evaluating the mechanisms associated with injury and injury prevention in pediatric sport. Finally, long-term studies are needed to identify the public health impact of pediatric sport injury.
\end{abstract}




\section{Introduction}

Sport injuries in children and adolescents may be predictable and potentially preventable $[1,2]$. However, it is impossible to eliminate all injury in youth sport. In some sports, the number and severity of injuries can be reduced through various injury prevention strategies. Though there is less research evidence specifically for the prevention of injuries in youth sport than in adult and elite sport, the impact of sport injury in this population warrants attention.

Participation in physical activity by children and adolescents has important implications for individual and public health benefits. Based on the Canadian Population Health Survey, $65 \%$ of adolescents reported participation in regular physical activity at least 12 times per month $[3,4]$. For adults, this has decreased significantly to less than $40 \%$ of the population over 18 participating in regular physical activity [4]. Similar findings are reported in other countries [5-9]. On average, children 5-12 years spend $18 \mathrm{~h}$ per week doing physical activity and youth $13-17$ years $15 \mathrm{~h}$ per week $[3,4]$. This provides ample opportunity for sport injury in this population. Also, $8 \%$ of adolescents drop out of recreational sporting activities annually because of injury [8].

Reduction of sport injury would have a major impact on quality of life through the maintenance and promotion of physical activity. There is epidemiological evidence that level of physical fitness is a significant predictor of allcause mortality, morbidity and disease-specific morbidity (i.e. cancer, cardiovascular disease, diabetes) [10-13]. Injuries are also a leading cause for the development of osteoarthritis (OA) in later life. There is evidence that knee and ankle injury, specifically, result in an increased risk of development of OA [14-16]. As such, there is a significant public health impact associated with these injuries and future development of OA and other diseases associated with decreased levels of physical activity. The benefits of sport participation in youth go beyond future health concerns, but also include the benefits of greater self-esteem, relaxation, competition, socialization, teamwork, fitness and greater motor skill development.

A four-stage approach has been proposed to study injury prevention [17]. First, surveillance must be used to measure the extent or magnitude of injury in a given population. Second, causes of injury or risk factors must be identified. Third, prevention strategies need to be developed and validated. Lastly, randomized controlled trials (RCTs) or other intervention studies should be conducted to measure the impact of the prevention strategy, again through surveillance. 


\section{Incidence of Injury in Pediatric Sport}

Prior to examining potential prevention strategies in child and adolescent sport, we must have a good understanding of the extent of the problem (incidence rates for injury), who is at risk (sport participation), and risk factors for injury in this population. Sport and recreation injuries are a major health problem in Canada and the USA. They represent a leading cause of injury morbidity in many age groups. There is evidence that sports are the leading cause of injury requiring medical attention, as well as emergency department admissions, in adolescents $[4,18-20]$. Sport injuries account for $50 \%$ of all injuries to secondary school children [21]. In Alberta, the reported cumulative incidence rate of adolescent (ages 15-19) sport injuries requiring medical attention is 26 injuries/100 adolescents/year [22]. Sport-specific injury incidence rates exceed this average number in sports such as football, hockey, basketball, wrestling, and gymnastics [5, 20, 22-29]. Studies which have examined only sport injuries reporting to hospital Emergency Departments report rates from 7.03 to 8.55 injuries/100 adolescents/year [18, 30, 31]. Cumulative incidence rates suggest the significance of the public health impact of sport injury. However, they do not take exposure to risk (i.e. hours of participation or number of athlete exposures) into consideration. Increasingly more sport-specific epidemiological studies have included exposure to risk into the study design, and estimate incidence density (i.e. number of injuries/ 1,000 participation hours or 1,000 athlete exposures) in the results. This facilitates the ability to examine injury risk factors as well as making comparisons across studies.

Acute trauma is one type of injury sustained in child and adolescent sport. In addition, there is growing concern about overuse injury in this population of athletes [32]. This likely reflects increased intensity of training and competition in sport at younger ages, increased skill level at younger ages and longer, often year-round, training seasons [32].

\section{Risk Factors for Injury in Pediatric Sport}

Risk factors in sport are any factors which may increase the potential for injury [2]. Risk factors may be extrinsic (i.e. weather, field conditions) or intrinsic (i.e. age, conditioning) to the individual participating in the sport. Modifiable risk factors refer to those which can be altered by injury prevention strategies to reduce injury rates $[2,19]$. Nonmodifiable risk factors, which cannot be altered, may affect the relationship between modifiable risk factors and 
Table 1. Potential risk factors for injury in child and adolescent sport

\begin{tabular}{ll}
\hline Extrinsic risk factors & Intrinsic risk factors \\
\hline $\begin{array}{l}\text { Non-modifiable } \\
\text { Sport played (contact/no contact) }\end{array}$ & $\begin{array}{l}\text { Non-modifiable } \\
\text { Pevel of play (recreational/elite) }\end{array}$ \\
$\begin{array}{l}\text { Position played } \\
\text { Weather }\end{array}$ & Sex \\
Time of season/Time of day & Potentially modifiable \\
& Fitness level \\
Potentially modifiable & Preparticipation sport specific \\
Rules & Training \\
Playing time & Flexibility \\
Playing surface (type/condition) & Strength \\
Equipment (protective/footwear) & Joint stability \\
& Biomechanics \\
& Balance/Proprioception \\
& Psychological/Social factors \\
\hline
\end{tabular}

injury. Identification of these factors will assist in defining high-risk populations. Potential risk factors are listed in table $1[1,19,33]$.

Much of the literature addressing child and adolescent sport injury is sport specific and based on descriptive data, which portray primarily the extent of the injury problem. There is a substantial body of literature accumulated over the past decade which demonstrates that risk factors are identifiable for sport- and recreation-related injuries in the adult and elite populations. The evidence for injury prevention strategies reducing the risk of injury in youth sport is weaker and based primarily on cohort studies for specific injuries in specific sports. There is some epidemiological evidence that modifiable risk factors (i.e. decreased levels of sport-specific training in the off-season, endurance, strength and balance) do increase the risk of injury in sports [1,34-40]. Most of these studies, however, address adult populations and are sport and/or injury specific.

\section{Nonmodifiable Risk Factors for Injury in Pediatric Sport}

In identifying nonmodifiable risk factors for injury in child and adolescent sport, there is evidence that males are generally at greater risk for injury $(\mathrm{OR}=1.16-2.4)[6,29,31,41-43]$. The exception to this is in studies examining specific sports including soccer, baseball, and basketball where females appear to be at greater risk [29,31, 41-44]. Male children and adolescents participating in sport may generally be at a greater risk of injury as they may be more aggressive, have larger body mass and experience greater contact 
compared to girls in the same sports. All of these factors may lead to increased forces in running, jumping, pivoting, and contact which may increase susceptibility to injury. In soccer, baseball, and basketball, studies show an increased risk of injury in girls. The reasons for this may be due to lower skill level, or may be of a physiological nature.

Left-handedness also appears to be a risk factor for injury [45]. Lefthanded adolescents may be at increased risk of injury because of environmental biases in a right-handed world (i.e. equipment used in sport) or functional differences related to neurological development [45].

Re-injury rates range from 13.1 to $38 \%$ [1, 23, 24, 28, 46, 47]. The risk of re-injury in some sports is greater than the risk of first-time injury $(\mathrm{RR}=1.35-1.7)$ [48-50]. Previous injury clearly increases the risk of injury in sport. This finding may be related to persistent symptoms, underlying physiological deficiencies resulting from the initial injury (i.e. ligamentous laxity, muscle strength, endurance, proprioception) and/or inadequate rehabilitation.

Sport-specific rates of injury vary considerably, with the highest rates of injury reported for boys participating in hockey [26, 27], basketball [5, 23, 29] and football $[28,29]$ and for girls participating in gymnastics [18, 29], basketball $[5,23]$, and soccer $[5,23,51]$. The lowest rates of injury are consistently reported in swimming, tennis, and badminton [5, 23, 29]. It is not surprising that hockey, basketball, and football are consistently among the top-rated sports for injury in male athletes. There is certainly body contact involved in two of the three sports (hockey and football), and some contact in basketball also. All three sports involve a high rate of jumping, sprinting, and pivoting activity, which are often involved in the mechanism of injury in sport. The findings of Backx et al [5] of outdoor sports, high jump rate sports, and contact sports increasing the risk of injury are consistent with the high rates of injury in these three sports. It is also not surprising that gymnastics, basketball, and soccer are consistently among the top-rated sports for injury in female athletes. These three sports also involve a high rate of jumping, sprinting, and pivoting activities.

The risk of injury consistently increases with age across studies $[6,23$, $27-29,44,48,52-59]$. In all sports, adolescents ( $>13$ years) are at a greater risk of injury than younger children [6, 23, 27-29, 44, 48, 52-59]. The peak injury rate is consistently in the oldest adolescent age group in youth studies examining all sports, soccer, hockey, football, baseball, and gymnastics [6, 23, 27-29, 44, 55, 59]. Consistency in these findings is not surprising, as level of competition, contact, and size typically increase with age. The time participating in sports likely increases with age and experience. However, exposureadjusted injury rate (i.e. incidence density) is not always examined.

Injury rates decrease with increasing skill level in hockey [27] and increase with increasing skill level in wrestling and gymnastics [27, 46, 52]. Risk of 
injury increases with organized sport versus unorganized sport [29], amount of time spent doing sporting activity [42], competition versus practice [37, 52], tournament play versus regular season play $[26,51]$, increased level of competition [23], indoor versus outdoor soccer [53,60], and large field size and reduced number of players in Australian Rules football [55]. Injury reporting may be more accurate in studies examining organized sport (i.e. levels of competition) and tournament play accounting for higher injury rates than in unorganized sport. In addition, competitors are more likely to be playing at greater intensity and speeds in competition and tournaments than in practice and regular season play, increasing the risk of sustaining an injury. In Australian Rules football, it is not surprising that larger field size and fewer players (i.e. likely reducing the risk of contact) appear to be associated with a lower risk of injury [55].

There is conflicting evidence regarding anthropometric measurement and risk of injury which appears to be injury and sport specific. Brust et al. [27] demonstrate an increased risk of injury in lighter hockey players with the same age and experience. In football, however, where age categories are also restricted by weight categorization, heavier players are at higher risk of injury than lighter boys $[28,55,61,62]$. In gymnastics, athletes who are taller or heavier are at an increased risk of injury compared with those shorter or lighter $[56,58,63]$. In soccer, Backous et al. [44] demonstrate that taller players are at an increased risk of injury compared with shorter players. Lyman et al. [54] demonstrate increased risk of elbow symptoms in pitchers who are heavier and taller. Taller and heavier athletes (i.e. in football, gymnastics, soccer, and baseball) may be more susceptible to injury due to greater forces being absorbed through soft tissue and joints. In hockey, a contact sport where there is no weight classification, it is not surprising that the smaller players are more susceptible to injury. Although skeletal maturity may not in itself be a modifiable risk factor, in the context of sport it may be considered modifiable in some sports such as hockey by grouping children by skeletal rather than chronological age.

With rapid skeletal growth occurring in children and adolescents, there are potentially physiological reasons why children and adolescents may be at an increased risk of injury [64]. For example, sudden intense muscular traction exerted on an immature skeleton (i.e. during a period of rapidly increasing muscular strength) may result in an acute avulsion fracture of a growth plate, an injury not possible in adulthood [64]. Chronic repetitive muscular traction exerted on an immature skeleton, usually at the time of a growth spurt, may result in traction apophysitis (i.e. Osgood-Schlatter or Sever's disease) [64]. These are both injuries exclusive to children and adolescents. There is also evidence that there is a noteworthy association between peak height velocity and 
peak fracture rate of the distal radius, suggesting that a growth spurt may increase the risk of some athletes to some injuries [65].

\section{Potentially Modifiable Risk Factors for Injury in Pediatric Sport}

Most studies examining biomechanical alignment, flexibility or strength demonstrate no association of these factors with injury in child and adolescent sport [1, 66-70]. The exceptions to this are found in sport-specific studies. In gymnastics and figure skating there is some evidence of an association between poor flexibility and injury $[58,71]$. Both anterior tibiofemoral laxity and pronation are predictive of anterior cruciate ligament knee injury in adolescents [72]. Pasque and Hewett [52] demonstrate an increased risk of shoulder injury in wrestling with increased shoulder ligament laxity. Decreased flexibility is not a risk factor generally for injury in adolescent [1, 69, 70] or adult sport [73]. However, it may be a risk factor for injury in gymnastics, figure skating, and wrestling, all sports that demand a high degree of flexibility for execution of many maneuvers $[58,71]$.

There is conflicting evidence that elbow injury in baseball pitchers is related to pitching style $[68,74]$. Albright et al. [74] found an increased risk of elbow injury with a horizontal arm during delivery (particularly with a whipping or snapping motion) in Little League pitchers ( $\leq 14$ years). Grana and Rashkin [68] found no relationship between injury and sidearm delivery or speed of delivery in older pitchers (14-19 years). Fatigue based on number of pitches in a game and number of pitches in a season seems to be associated with an increased risk of elbow injury [54]. Fatigue also appears to play a role in hockey where there is an increased risk of injury in the last $5 \mathrm{~min}$ of a period and the last period of a game [37]. Lysens et al. [1] report an increased risk of injury in young women with decreased endurance fitness. This is consistent with Cahill and Griffith [40] who found that adolescent football players participating in a preseason conditioning program were at significantly decreased risk of knee injury.

Psychosocial factors may also be potentially modifiable. Faelker et al. [75] demonstrate evidence of a dose-response gradient between decreasing socioeconomic status and increased risk of injury. Studies consistently demonstrate a high correlation between injury in sport and life stress [76-79]. These findings are also consistent with the findings for other injury types (i.e. home, fall, and traffic injury) $[75,78,79]$.

Less than $40 \%$ of high school rugby participants $(n=2,330)$ completed any preseason training [80]. High rates of injury may be related to decreased endurance and/or strength associated with limited preseason training, as indicated in both adolescent $[1,40,53,81,82]$ and adult $[35,36,83]$ study findings. Some athlete populations (i.e. low-skill division adolescent female soccer 
players) may benefit from training programs while others (i.e. high-skill division adolescent female soccer players) may not [81]. Proprioceptive balance training, in conjunction with other training techniques, may reduce the risk of specific injury in specific sport [82-84]. The impact of decreased proprioception as a risk factor for injury remains unclear.

\section{Injury Prevention in Pediatric Sport}

As seen throughout sport-specific chapters in this book, as well as in the literature at large, there are very few prospective intervention studies addressing prevention strategies to reduce injury in youth sport. A summary of the prospective intervention studies is shown in table 2 [53, 66, 81, 82, 85-89]. These prevention strategies potentially target risk factors, such as limitations in flexibility, strength, endurance, and proprioception/balance. A nonrandomized prospective intervention study shows no effect of a half-time warm-up and stretching program in high school football [66]. Hewett et al. [85] demonstrate in a nonrandomized prospective study that extensive neuromuscular training programs including flexibility, strength, landing skills, and plyometrics may be effective in reducing injury in adolescent basketball, soccer, and volleyball. In soccer, a significant protective effect of a specific education, conditioning and rehabilitation program in adolescent soccer players is found in the low-skilled division only [RR $=0.63(95 \% \mathrm{CI} ; 0.42-0.94)$ ] [82]. Mykelbust et al. [86] also demonstrate a protective effect of a comprehensive sport-specific balancetraining program in the reduction of anterior cruciate ligament injuries in elite adolescent female European handball players in a nonrandomized prospective intervention study. There were only four RCTs identified in a youth population. Emery et al. [87] have demonstrated a protective effect of a home-based balance training program using a wobble board in the reduction of all sportrelated injuries in high school physical education participants $[R R=0.2(95 \%$ CI; 0.05-0.88)]. Heidt et al. [53] also demonstrate a protective effect of a multifaceted 7-week preseason training program in female high school soccer players [RR $=0.42(95 \% \mathrm{CI} ; 0.2-0.91)]$. Wedderkopp et al. [82] demonstrate a significant reduction of injury in adolescent female European handball with the use of a multifaceted training program which included proprioceptive balance training using a wobble board $[\mathrm{RR}=0.17$ (95\% CI; 0.09-0.32)]. In a further study, they also demonstrate the protective effect of balance board training alone in the reduction of injury in female European handball $[R R=0.21(95 \%$ CI; 0.09-0.53)] [88].

As there are relatively few epidemiological studies addressing modifiable risk factors for injury in child and adolescent sport, it is prudent to discuss 
Table 2. Studies examining prevention strategies for injury in child and adolescent sport

\begin{tabular}{|c|c|c|c|c|c|}
\hline Author (year) & $\begin{array}{l}\text { Study design } \\
\text { (country and } \\
\text { time frame) }\end{array}$ & $\begin{array}{l}\text { Participants } \\
\text { (age) }\end{array}$ & $\begin{array}{l}\text { Prevention } \\
\text { strategy }\end{array}$ & $\begin{array}{l}\text { Injury } \\
\text { definition }\end{array}$ & $\begin{array}{l}\text { Results (relative risk }=\mathrm{RR} \text {, } \\
\text { odds ratio }=\mathrm{OR} \text {, provided } \\
\text { adequate information is } \\
\text { available) }\end{array}$ \\
\hline $\begin{array}{l}\text { Bixler and Jones } \\
\text { [66] (1992) }\end{array}$ & $\begin{array}{l}\text { Non-RCT } \\
\text { (USA) }\end{array}$ & $\begin{array}{l}\text { High school } \\
\text { football players } \\
\text { ( } 5 \text { teams: } \\
3 \text { intervention, } \\
2 \text { control) }\end{array}$ & $\begin{array}{l}\text { 1. Intervention: } \\
1 / 2 \text { time warm-up and } \\
\text { stretching exercises } \\
\text { 2. Control: no exercises }\end{array}$ & $\begin{array}{l}\text { Injury requiring } \\
\text { medical attention }\end{array}$ & $\begin{array}{l}\text { Injury rates between } \\
\text { groups not statistically } \\
\text { significant (insufficient } \\
\text { data to calculate RR) }\end{array}$ \\
\hline $\begin{array}{l}\text { Emery et al. } \\
\text { [87] (2004) }\end{array}$ & $\begin{array}{l}\text { Cluster RCT } \\
\text { (Canada) }\end{array}$ & $\begin{array}{l}120 \text { high school } \\
\text { physical } \\
\text { education } \\
\text { students (14-18) } \\
\text { (10 schools) }\end{array}$ & $\begin{array}{l}\text { 1. Intervention: daily } \\
\text { progressive home } \\
\text { program using wobble } \\
\text { board } \\
\text { 2. Control: no treatment }\end{array}$ & $\begin{array}{l}\text { Injury occurring } \\
\text { during a sporting } \\
\text { activity which } \\
\text { required medical } \\
\text { attention and/or } \\
\text { loss of at least one } \\
\text { day of sporting } \\
\text { activity }\end{array}$ & $\begin{array}{l}\mathrm{RR}=0.20(95 \% \mathrm{CI} ; \\
0.05-0.88) \\
\text { RR (ankle sprain) }=0.14 \\
(95 \% \text { CI; 0.18-1.13). } \\
\text { Multivariate analysis + } \\
\text { control for cluster } \\
\text { randomization. Greatest } \\
\text { effect in those with } \\
\text { previous injury. Also } \\
\text { demonstrated dose- } \\
\text { response effect based on } \\
\text { improvements in timed } \\
\text { static and dynamic } \\
\text { balance. }\end{array}$ \\
\hline $\begin{array}{l}\text { Heidt et al. } \\
\text { [53] (2000) }\end{array}$ & RCT (USA) & $\begin{array}{l}300 \text { female high } \\
\text { school soccer } \\
\text { players }(14-18)\end{array}$ & $\begin{array}{l}\text { 1. Intervention: } 7 \\
\text { week preseason Frappier } \\
\text { acceleration program } \\
\text { (cardio-vascular, } \\
\text { plyometrics, strength } \\
\text { and flexibility) } \\
\text { 2. Control: no preseason } \\
\text { program }\end{array}$ & $\begin{array}{l}\text { Injury requiring } \\
\text { missing at least } 1 \\
\text { game or practice }\end{array}$ & $\begin{array}{l}\mathrm{RR}=0.42 \\
\quad(95 \% \mathrm{CI} ; 0.2-0.9)\end{array}$ \\
\hline
\end{tabular}



Hewett et al.
[85]
Non-RCT
(USA)

$$
\begin{aligned}
& \text { Junge et al. } \\
& \text { [81] (2002) }
\end{aligned}
$$

\section{Non-RCT \\ (Switzerland)}

Marshall et al Non-RCT [89] (2003)
194 soccer
players
$($ mean $=16.5)$ coach and player education, rehabilitation + conditioning program including cardio-vascular, strength, flexibility and plyometrics training

2. Control: ill-defined volleyball and basketball players) (includes flexibility, strength, plyometrics, weight training and landing techniques)

2. Control 1: 463 girls

3. Control 2: 434 boys

1. Reduced-impact safety

Little League baseball players (5-18)

traditional ball

2. Faceguard vs. no
Serious knee injury faceguard (ligament sprain) seen

by athletic therapist

( $>5$ days time loss)

14 serious knee injuries ( 2 intervention, 2 male control, 10 female control)

$\mathrm{RR}=0.42$ (male)

$\mathrm{RR}=0.17$ (female)

Significant based on

Chi-square analysis $(p=0.05)$. No control for sport type or factors other than gender

1. $\mathrm{RR}=0.82(95 \% \mathrm{CI}$; 0.58-1.15) physical complaint $>2$ weeks or missed session

2. RR (high-skilled divisions) $=0.94$ (95\% CI; 0.58-1.5)

3. RR (low-skilled divisions) $=0.63$ (95\% CI; 0.42-0.94)

1. RR (safety ball $)=0.72$ (95\% CI; 0.57-0.91)

2. $\mathrm{RR}($ faceguard $)=0.65$ (95\% CI; 0.43-0.98) 
Table 2 (continued)

\begin{tabular}{|c|c|c|c|c|c|}
\hline Author (year) & $\begin{array}{l}\text { Study design } \\
\text { (country and } \\
\text { time frame) }\end{array}$ & $\begin{array}{l}\text { Participants } \\
\text { (age) }\end{array}$ & $\begin{array}{l}\text { Prevention } \\
\text { strategy }\end{array}$ & $\begin{array}{l}\text { Injury } \\
\text { definition }\end{array}$ & $\begin{array}{l}\text { Results (relative risk }=\mathrm{RR} \text {, } \\
\text { odds ratio }=\mathrm{OR} \text {, provided } \\
\text { adequate information is } \\
\text { available) }\end{array}$ \\
\hline $\begin{array}{l}\text { Myklebust et al. } \\
\text { [86] (2003) }\end{array}$ & $\begin{array}{l}\text { Non-RCT } \\
\text { over } 3 \text { seasons } \\
(60,58,52 \\
\text { teams/season) } \\
\text { (Norway) }\end{array}$ & $\begin{array}{l}\text { Female } \\
\text { European } \\
\text { team handball } \\
\text { players }(16-18)\end{array}$ & $\begin{array}{l}\text { 1. Control year } \\
\text { 2. } 1 \text { st intervention } \\
\text { season }- \text { floor, balance } \\
\text { matt and wobble board } \\
\text { exercises }(15 \text { min }) \\
\text { (handout }) \text { - video }+ \\
\text { coach delivered } \\
(3 \times / \text { week for } 5-7 \text { weeks } \\
\text { and } 1 \times / \text { week for season }) \\
3.2 \text { nd intervention season }- \\
\text { as above but physiotherapist } \\
\text { delivered at every practice } \\
(15 \text { min })(3 \times / \text { week for } \\
5-7 \text { weeks and } 1 \times / \text { week } \\
\text { for season })\end{array}$ & $\begin{array}{l}\text { Anterior cruciate } \\
\text { ligament injury } \\
(>1 \text { week time loss }= \\
\text { suspected) as assessed } \\
\text { by PT }\end{array}$ & $\begin{array}{l}\text { OR }(1 \mathrm{st})=0.87 \\
(95 \% \text { CI; } 0.5-1.52) \\
\text { OR }(2 \mathrm{nd})=0.64(95 \% \\
\text { CI; 0.35-1.18) OR elite } \\
\text { division }(2 \mathrm{nd})=0.37 \\
(95 \% \text { CI; } 0.13-1.05)\end{array}$ \\
\hline $\begin{array}{l}\text { Wedderkopp et al. } \\
\text { [82] (1999) }\end{array}$ & $\begin{array}{l}\text { RCT } \\
\text { (Denmark, } \\
\text { 1995/96) }\end{array}$ & $\begin{array}{l}237 \text { female } \\
\text { European } \\
\text { team handball } \\
\text { players }(16-18)\end{array}$ & $\begin{array}{l}\text { 1. Intervention: practice } \\
\text { session training program } \\
\text { (warm-up with } 2 \text { or } \\
\text { more functional large } \\
\text { muscle group exercises } \\
\text { and proprioceptive } \\
\text { ankle disk activity) } \\
\text { 2. Control: nonspecific } \\
\text { practice session training }\end{array}$ & $\begin{array}{l}\text { Injury requiring } \\
\text { player to miss } \\
\text { next session or } \\
\text { unable to } \\
\text { participate without } \\
\text { considerable } \\
\text { discomfort }\end{array}$ & $\begin{array}{l}\mathrm{RR}=0.17 \\
(95 \% \text { CI; 0.09-0.32) }\end{array}$ \\
\hline
\end{tabular}


Wedderkopp

et al. [88]

(2003)

Cluster

RCT

(Denmark)
16 teams female

European team

handball players

(16-18)
1. Intervention: practice session included

10-15 min use of individual ankle disk and warm-up with 2 or more functional large muscle group exercises as in previous study

2. Control group: no ankle disk
Injury requiring player to miss next session or unable to participate without considerable discomfort
$\mathrm{OR}=0.21(95 \% \mathrm{CI}$;

0.09-0.53)

Multivariate analysis

discomfort but no contro of cluster randomization

in analysis

Increased risk with increased time in match play

$\mathrm{RCT}=$ randomized controlled trials 
epidemiological evidence in adult sport prior to making recommendations for future research. There is inadequate evidence to support decreased muscle strength, globally, as a risk factor for injury in sport. Emery [34] concludes, based on a systematic review of the literature, that there is evidence of an association between decreased hamstring strength and hamstring strain injury in sport. In a review of the literature, Gleim and McHugh [73] finds no strong evidence that decreased flexibility is associated with injury in sport. There is evidence that decreased sport-specific training in the off-season in professional hockey increased the risk of groin strain injury $[\mathrm{RR}=3.38(95 \% \mathrm{CI}$; $1.45-7.92)$ ] [90]. Poor endurance is a risk factor for injury amongst army trainees during the basic training $[\mathrm{RR}=2.8(95 \% \mathrm{CI}$; $1.2-6.7)$ for men and 1.69 (95\% CI; 1.2-2.4) for women] [36]. Previous injury appears to be the most significant predictor of sports injury in some studies, with relative risks ranging from 2.88 to $9.41[17,35,84]$. Tropp et al. [39] demonstrate that soccer players with functional ankle instability and decreased balance ability were at significantly greater risk of ankle sprain reinjury.

A systematic review of the literature concludes that there are few welldesigned studies examining prevention strategies for injury in sport at any age [91]. There are some prospective studies demonstrating the protective effect of equipment in various sports in preventing injury. In baseball and softball, break-away bases reduce sliding injuries significantly $[92,93]$. Ankle taping and ankle braces reduce ankle sprain injury in basketball $[42,94]$. In ice hockey, full face shields reduce head and face injury [95-98]. Rule modification may also decrease the risk of injuries in some adolescent sports. In football, the elimination of spear tackles significantly reduced the number of head and neck injuries $[49,99]$. In ice hockey, fair play rules and making checking from behind illegal significantly reduced overall injury as well as head/neck and back injuries specifically $[100,101]$. There is other adult and elite population RCT evidence that balance training in conjunction with other preseason training strategies (i.e. strengthening, endurance training, plyometrics) reduce the incidence of specific injury in specific sports [83, 84, 86, 102-105]. These multifaceted training programs reduce the incidence of ankle sprain injuries and anterior cruciate ligament injuries in some sports. However, balance, endurance, and strength have not been examined as outcome measurements, so it is not clear as to the impact of the training strategies on these potential risk factors.

Protective equipment in many sports (i.e. full face masks and mouth guards in hockey, face shields and safety balls in baseball, shin pads in soccer, helmets in cycling, skiing and snowboarding) exerts a protective effect $[89,95$, 106-107]. Regardless, the challenge remains to engage youth in the use of such equipment. Despite the ongoing controversies, educational strategies in 
combination with legislation or facility/sport association requirements may be the best approach to increasing the use of some protective equipment in some sports.

There is increasing enthusiasm regarding the importance of a preparticipation evaluation by physicians, physiotherapists, and athletic trainers caring for various pediatric athlete populations. The effectiveness of preparticipation evaluation in the prevention of injury in the pediatric population, however, has not been evaluated. Wingfield et al. [108] suggest, based on the results of a systematic review of the literature, that it is difficult to find data to support a specific approach to the preparticipation evaluation or to establish best practices for risk factor identification in any population. As such, standardization of the process is critical prior to attempting to evaluate its effectiveness in any athlete population, including the pediatric population.

\section{Study Limitations in Injury Prevention in Pediatric Sport}

To target specific populations of adolescents with those sport-specific training strategies that will have the greatest population health impact; sport participation rates, sports injury rates, and safety behaviors require further examination. Once a specific sport has been targeted for prevention of injury, valid sport injury surveillance systems, including participation exposure and injury data acquisition, require development.

One of the fundamental difficulties in comparing research in sport injury epidemiology is the variability in research design, measurements used to assess exposure and injury, and the variety of risk factors and sports assessed in studies. The research designs reviewed are almost exclusively observational, and intervention studies are not always RCTs. The temporal association between exposure and outcome is often ignored in cross-sectional and case-control studies. For example, Smith et al. [71] examine flexibility in figure skaters already presenting with knee pain, and the temporal association between knee pain and decreased flexibility is unclear.

Injury definition and methods of injury data collection are extremely variable. A major limitation in many studies reviewed is that incidence rates based on number of participants rather than incidence densities based on exposure (i.e. hours or sessions of participation) are used to distinguish high-risk athletes. Clearly, time spent doing an activity is critical in the assessment of risk of injury. Time loss, medical requirements, and reinjury inclusion differ widely between injury definitions. Methods of data collection vary from self-report to therapist or physician report. Only $25-31 \%$ of injuries in some studies resulted in a physician consult $[5,23,24]$. Depending on injury definition, some studies 
may underestimate injury if only those reporting to an emergency room $[18,30$, $31,109]$, physician, or therapist [37, 51] are included. Other studies may overestimate injury rates if all injuries are reported regardless of reporting source (i.e. parent, coach) [5, 23]. If one relies on self-report, particularly over a longer time frame, incidence rates will likely be underestimated due to recall bias. Bijur et al. [6] demonstrate a $51 \%$ increase in self-reported injury over a onemonth recall period compared to a 12 -month recall period.

Selection bias is of concern in many studies as there is no random selection of participants. Selection bias in which athletes more likely to be injured (i.e. previous injury) and more likely to be in exposure-risk group are selected, may lead to an overestimation of association between risk factor and injury $[1,40,56,71,72,75,78,79,110]$. If there are unreported drop-outs from the study and the reason for drop-out is related to injury, this may lead to an underestimation of association, another form of selection bias. Lack of blinding to exposure status, as with most of the cohort studies examined in this review, may also lead to overestimation of the association.

Poor reliability and validity of exposure measurements (i.e. flexibility, strength) resulting in nondifferential misclassification of exposure (i.e. likelihood of misclassification of exposure is not associated with outcome) will underestimate the association between exposure and injury. This is certainly of concern in studies which demonstrate no association [1, 66, 68-70].

The most noteworthy source of bias in the studies reviewed was a lack of measurement and control for potentially confounding variables. This results most often in an overestimation of association between exposure and injury. When recruitment of subjects is not random, risk factors/training interventions assessed may not be the only difference between groups. Differences in physiological factors, coaching technique, warm-up routines, and equipment may prevail. For example, in Cahill and Griffith's [40] study, a historical cohort, differences attributed to preseason conditioning may be a result of equipment differences, coaching differences, rule changes (i.e. elimination of below the waist blocking in 1973) [111], or physiological factors in the two cohorts, which were not controlled for in the study.

In some RCT studies examining prevention strategies, the intervention was assigned to a team (i.e. cluster), not an individual [53, 81, 82]. If similarities within a team are greater than similarities between teams, these similarities should be controlled for in the analysis (i.e. cluster-adjusted analysis). When clusters are controlled for in an analysis, the effect measure is less precise (i.e. larger 95\% CIs) if similarities within each cluster are in fact greater than similarities between clusters [112]. As such, overestimates of the protective effects of training strategies may have been reported as a result of the individual level analyses performed in these intervention studies. In addition, the intervention 
studies examined identify multifaceted preventative training programs $[53,66$, $81,82]$. As a result, it is difficult to identify specific risk factors addressed by the program (i.e. flexibility, strength, endurance, balance) if measurements of these factors are not examined.

External validity of the results in all of the studies examined is limited due to limitations in internal validity. Certainly generalizability beyond the specific sport, age group, level of competition and specific injury type is limited.

In examining Hill's criteria of causation [113], many of the studies reviewed are consistent with the findings in adult population studies. The strength of the associations found between preparticipation training programs and injury are convincing based on the magnitude of the associations found, despite concerns with internal validity and individual level analysis. Specificity, implying that a specific cause leads to a specific effect is difficult to identify when studies often do not control for other risk factors, and injury outcome is often global and poorly defined. Temporal association is clear only in the cohort studies and RCTs reviewed. The only studies providing a clear indication of a dose-response relationship are Faelker's [75], in which injury rate increases with increasing level of poverty and the studies examining increased risk of injury with increasing age $[6,23,28,48,54,56]$. Biological plausibility of risk factors and coherence to existing knowledge has been discussed. Injury prevention studies are few, thus experimental evidence is limited.

\section{Conclusions and Future Research in Injury Prevention in Pediatric Sport}

Child and adolescent participation rates in sport are high. High rates of sport injury in this population have a substantial impact on the individual, their parents, and the health care system. Sport injury in children and adolescents may also potentially affect future involvement in physical activity and the future health of our population.

The strength of the evidence for potentially modifiable risk factors for injury in children and adolescents is limited by research design and concerns with internal validity. In case-control and cross-sectional study designs, the temporal association between exposure and outcome is unclear. In many of the cohort studies and nonrandomized intervention studies reviewed, various sources of bias in the selection of subjects, measurement of exposure and outcome variables and lack of control for other potentially confounding variables threaten the internal validity of the studies. There is limited RCT evidence supporting preventative training programs in specific sports in adolescents to reduce the risk of injury. There is more convincing evidence in adult 
epidemiological studies that decreased endurance, decreased strength, decreased balance, and decreased preseason sport-specific training are associated with sports injury. The consistency of the findings between child and adolescent studies reviewed and the adult population studies is encouraging.

Given the limited number of prospective studies found in the pediatric sport injury literature, it is very likely that other risk factors have not been identified to date, much less evaluated adequately. For example, it is possible that coaching factors (i.e. style, education and certification) may play an important role in injury risk and prevention in various pediatric athlete populations. Other examples may include cross-training, sleep patterns, nutrition, and numerous additional psychosocial factors to those previously identified.

Evidence from descriptive epidemiological studies can be utilized in targeting relevant athlete groups [i.e. high-risk sports such as hockey, basketball, football, soccer (particularly indoor), and gymnastics], age groups (i.e. older adolescents) and skill levels (i.e. low-skill division in female adolescent soccer) in designing future research examining risk factors and prevention strategies in child and adolescent sport. Future studies examining prevention strategies such as preseason conditioning and proprioceptive balance training are warranted. Future RCTs examining optimal sport-specific injury prevention strategies should quantify and control for potential risk factors for injury in child and adolescent sport. It is critical to integrate basic science, laboratory and epidemiological research to maximize the understanding of mechanisms of injury, risk factors for injury, optimal prevention strategies, complete and appropriate treatment (i.e. medical, surgical and rehabilitation), and long-term effects of injury in youth sport. Long-term follow-up studies should be part of the future vision for research in injury prevention in youth sport. These will be critical, quantifying the long-term impact of pediatric sport injuries on future sport participation and the implications for the future health of our population (i.e. development of OA and other disease morbidity and mortality).

\section{References}

1 Lysens R, Steverlynck A, van den Auweele Y, Lefevre J, Renson R, Claessens A, et al: The predictability of sports injuries. Sports Med 1984;1:6-10.

2 Meeuwisse WH: Predictability of sports injuries: What is the epidemiological evidence? Sports Med 1991;12:8-15.

3 Canadian Fitness and Lifestyle Research Institute: http://www.cflri.ca/cflri/resources/ pub.php\#98pamrep. 2003.

4 Statistics Canada. Culture and Tourism Division: Canada's culture and heritage and identity: A statistical perspective. Ottawa, Ministry of Industry, 1997.

5 Backx FJG, Beijer HJM, Bol E, Erich WBM: Injuries in high-risk persons and high-risk sports. A longitudinal study of 1818 school children. Am J Sports Med 1991;19:124-130. 
6 Bijur PE, Trumble A, Harel Y, Overpeck MD, Jone D, Scheidt PC: Sports and recreation injuries in US children and adolescents. Arch Pediatr Adolesc Med 1995;149:1009-1016.

7 Grimmer KA: Young people's participation in sports and recreational activities, and associated injury. South Australia, University of South Australia and Sports Medicine Australia, 1999.

8 Grimmer KA, Jones D, Williams J: Prevalence of adolescent injury from recreational exercise: An Australian perspective. J Adolesc Health 2000;27:1-6.

9 Northern Sydney Area Health Services, New South Wales Youth Injury Report, 1997.

10 Blair SN: Physical activity, physical fitness and health. Res Q Exerc Sport 1993;64:365-376.

11 Blair SN, Kohl HW, Barlow CE: Changes in physical fitness and all-cause mortality: A prospective study of healthy and unhealthy men. JAMA 1995;273:1093-1098.

12 Jebb S, Moore M: Contribution of a sedentary lifestyle and inactivity to the etiology of overweight and obesity: Current evidence and research issues. Med Sci Sports Exerc 1999;31:S534-S541.

13 Paffenbarger RS, Kamput JB, Lee IM: Changes in physical fitness and other lifestyle patterns influence longevity. Med Sci Sports Exerc 1994;26:857-865.

14 Daniel DM, Stone ML, Dobson BE: Fate of the ACL injured patient. A prospective outcome study. Am J Sports Med 1994;22:632-644.

15 Drawer F, Fuller CW: Propensity for osteoarthritis and lower limb joint pain in retired professional soccer players. Br J Sports Med 2001;35:402-408.

16 Gillquist J, Messner K: Anterior cruciate ligament reconstruction and the long-term incidence of gonarthrosis. Sports Med 1999;27:143-156.

17 van Mechelen W: Sports injury surveillance. One size fits all? Sports Med 1997;24:164-168.

18 Bienefeld M, Pickett W, Carr PA: A descriptive study of childhood injuries in Kingston, Ontario, using data from computerized injury surveillance system. Chronic Dis Can 1996;17:21-27.

19 Emery C: Risk factors for injury in child and adolescent sport: A systematic review of the literature. Clin J Sport Med 2003;13:256-268.

20 King MA, Pickett W, King ALJ: Injury in Canadian youth: A secondary analysis of the 1993-94 health behaviour in school-aged children survey. Can J Public Health 1998;89:397-401.

21 Abernethy L, MacAuley D: Impact of school sports injury. Br J Sports Med 2003;37:354-355.

22 Mummery WK, Spence JC, Vincenten JA, Voaklander DC: A descriptive epidemiology of sport and recreation injuries in a population-based sample: Results from the Alberta Sport and Recreation Injury Survey. Can J Public Health 1998;89:53-56.

23 Backx FJG, Erich WBM, Kemper ABA, Verbeek ALM: Sports injuries in school-aged children. An epidemiologic study. Am J Sports Med 1989;17:234-240.

24 McLain LG, Reynolds S: Sports injuries in a high school. Pediatrics 1989;84:446-450.

25 Messina DF, Farney WC, DeLee JC: The incidence of injury in Texas high school basketball. A prospective study among male and female athletes. Am J Sports Med 1999;27:294-299.

26 Roberts WO, Brust JD, Leonard BO: Youth ice hockey tournament injuries: Rates and patterns compared to season play. Med Sci Sports Exerc 1999;31:46-51.

27 Brust JD, Leonard BJ, Pheley A, Roberts WO: Children's ice hockey injuries. Am J Dis Child 1992;146:741-747.

28 Goldberg B, Rosenthal PP, Robertson LS, Nicholas JA: Injuries in youth football. Pediatrics 1988;81:255-261.

29 Zaricznyj B, Shattuck LJM, Mast TA, Robertson RV, D'Elia G: Sports-related injuries in school aged children. Am J Sports Med 1980;8:318-324.

30 Gallagher S, Finison K, Guyer B, Goodenough S: The incidence of injuries among 87,000 Massachusetts children and adolescents: Results of the 1980-81 statewide childhood injury prevention program surveillance system. Am J Public Health 1984;74:1340-1347.

31 Sorensen L, Larsen S, Rock N: The epidemiology of sports injuries in school aged children. Scand J Med Sci Sports 1996;6:281-286.

32 Stanitski CL, DeLee JC, Drez D (eds): Pediatric and Adolescent Sports Medicine. Philadelphia, WB Saunders Co, 1994

33 Caine DJ, Caine CG, Lindner KJ: Epidemiology of Sports Injuries. Illinois, Human Kinetics, 1996.

34 Emery CA: Does decreased muscle strength cause acute muscle strain injury in sport? A systematic review of the evidence. Phys Ther Rev 1999;4:79-85. 
35 Emery CA, Meeuwisse WH: Risk factors for groin and abdominal strain injury in the National Hockey League Preseason: A multivariate approach. Med Sci Sports Exerc 1999;9:1423-1433.

36 Jones BH, Bovee MW, Harris JM, Cowan DN: Intrinsic risk factors for exercise-related injuries among male and female army trainees. Am J Sports Med 1993;21:705-710.

37 Pinto M, Kuhn JE, Greenfield MLV, Hawkins RJ: Prospective analysis of ice hockey injuries at the Junior A level over the course of a season. Clin J Sport Med 1999;9:70-74.

38 Tropp H, Ekstrand J, Gillquist J: Stabilometry in functional instability of the ankle and its value in predicting injury. Med Sci Sports Exerc 1984;16:64-66.

39 Tropp H, Ekstrand J, Gillquist J: Factors affecting stabilometry recordings of single leg stance. Am J Sports Med 1984;12:185-188.

40 Cahill BR, Griffith EH: Effect of preseason conditioning on the incidence and severity of high school football knee injuries. Am J Sports Med 1978;6:180-184.

41 de Loes M: Epidemiology of sports injuries in the Swiss organization 'Youth and Sports' 1987-1989. Injuries, exposure and risks of main diagnoses. Int J Sports Med 1995;16:134-138.

42 Garrick JG, Requa RK: Role of external support in the prevention of ankle sprains. Med Sci Sports 1973;5:200-203.

43 Lenaway DD, Ambler AG, Beaudoin DE: The epidemiology of school-related injuries: New perspectives. Am J Prev Med 1992;8:193-198.

44 Backous DD, Friedl KE, Smith NJ, Parr TJ, Carpine WD: Soccer injuries and their relation to physical maturity. Am J Dis Child 1988;142:839-842.

45 Graham CJ, Cleveland E: Left-handedness as an injury risk factor in adolescents. J Adolesc Health $1995 ; 16: 50-52$.

46 Caine D, Knutzen K, Howe W, Keeler L, Sheppard L, Henrichs D, et al: A three-year epidemiological study of injuries affecting young female gymnasts. Phys Ther Sport 2003;4:10-23.

47 Caine D, Cochrane B, Caine C, Zemper E: An epidemiological investigation of injuries affecting young competitive female gymnasts. Am J Sports Med 1989;17:811-820.

48 Robey JM, Blyth CS, Mueller FO: Athletic injuries: Application of epidemiologic methods. JAMA 1971;217:184-189.

49 Mueller FO, Blyth CS: Fatalities from head and cervical spine injuries occurring in tackle football: 40 years experience. Clin Sports Med 1987;6:185-196.

50 Machold W, Kwasny O, Gassler P, et al: Risk of injury through snowboarding. J Trauma 2000;48:1109-1114.

51 Schmidt-Olsen S, Bunemann L, Lade V, Brassoe J: Soccer injuries of youth. Br J Sports Med 1985;19:151-154.

52 Pasque CL, Hewett TE: A prospective study of high school wrestling injuries. Am J Sports Med 2000;28:509-515.

53 Heidt RS, Sweeterman LM, Carlonas RL, Traub JA, Tekulve FX: Avoidance of soccer injuries with preseason conditioning. Am J Sports Med 2000;28:659-662.

54 Lyman S, Fleisig GS, Waterbor JW, Funkhouser EM, Pulley L, Andrews JR, et al: Longitudinal study of elbow and shoulder pain in youth baseball pitchers. Med Sci Sports Exerc 2001; 33:1803-1810.

55 McMahon KA, Nolan T, Bennett CM, Carlin JB: Australian rules football injuries in children and adolescents. Med J Aust 1993;159:301-306.

56 Steele VA, White JA: Injury prediction in female gymnasts. Br J Sports Med 1986;20:31-33.

57 Sullivan JA, Gross RH, Grana WA, Garcia-Moral CA: Evaluation of injuries in youth soccer. Am J Sports Med 1980;8:325-327.

58 Wright KJ, De Cree C: The influence of somatotype, strength and flexibility on injury occurrence among female competitive Olympic style gymnasts - A pilot study. J Phys Ther Sci 1998; 10:87-92.

59 Yde J, Nielsen AB: Sports injuries in adolescents' ball games: Soccer, handball and basketball. Br J Sports Med 1990;24:51-54.

60 Hoff G, Martin T: Outdoor and indoor soccer: Injuries among youth players. Am J Sports Med 1986;14:231-233.

61 Kaplan TA, Digel SL, Scavo VA, Arellana SB: Effect of obesity on injury risk in high school football players. Clin J Sport Med 1995;5:43-47. 

tive observational cohort analysis among players aged 9-13 years. Mayo Clin Proc 2002;77: 317-322.

63 Lindner KJ, Caine D: Physical and performance characteristics of injured and injury-free female gymnasts. J Hum Mov Stud 1993;25:69-83.

64 Armstrong N, van Mechelen W (eds): Paediatric Exercise Science and Medicine. New York, Oxford University Press, 2000.

65 Bailey DA, Wedge JH, McCulloch RG, Martin AD, Bernhardson SC: Epidemiology of fractures of the distal end of the radius in children as associated with growth. J Bone Joint Surg 1989; 71A:1225-1231.

66 Bixler B, Jones RL: High school football injuries: Effects of a post-halftime warm-up and stretching routine. Fam Pract Res J 1992;12:131-139.

67 Grace TG, Sweetser ER, Nelson MA, Ydens LR, Skipper BJ: Isokinetic muscle imbalance and knee-joint injuries. J Bone Joint Surg 1984;66A:734-740.

68 Grana WA, Rashkin A: Pitcher's elbow in adolescence. Am J Sports Med 1980;8:333-336.

69 Grubbs N, Nelson RT, Bandy WD: Predictive validity of an injury score among high school basketball players. Med Sci Sports Exerc 1997;29:1279-1285.

70 Maffulli N, King JB, Helms P: Training in elite young athletes (the Training of Young Athletes (TOYA) Study): Injuries, flexibility and isometric strength. Br J Sports Med 1994;28:123-136.

71 Smith AD, Stroud L, McQueen C: Flexibility and anterior knee pain in adolescent elite figure skaters. J Pediatr Orthop 1991;11:77-82.

72 Woodford-Rogers B, Cyphert L, Denegar CR: Risk factors for anterior cruciate ligament injury in high school and college athletes. J Athl Train 1994;29:343-346,376-377.

73 Gleim GW, McHugh MP: Flexibility and its effects on sports injury and performance. Sports Med 1997;24:289-299.

74 Albright JA, Jokl P, Shaw R, Albright JP: Clinical study of baseball pitchers: Correlation of injury to the throwing arm and method of delivery. Am J Sports Med 1978;6:15-21.

75 Faelker T, Pickett W, Brison RJ: Socioeconomic differences in childhood injury: A population based epidemiologic study in Ontario, Canada. Inj Prev 2000;6:203-208.

76 Kerr GA, Minden H: Psychological factors related to the occurrence of athletic injuries. J Sport Exerc Psychol 1988;10:167-173.

77 Kolt G, Kirby R: Injury in Australian competitive gymnastics: A psychological perspective. Aust J Physiother 1996;42:121-126.

78 Smith AM, Stuart MJ, Wiese-Bjornstal DM, Gunnon C: Predictors of injury in ice hockey players: A multivariate, multidisciplinary approach. Am J Sports Med 1997;25:500-507.

79 Smith RE, Smoll FL, Ptacek JT: Conjunctive moderator variables in vulnerability and resiliency research: Life stress, social support and coping skills, and adolescent sport. J Pers Soc Psychol 1990;58:360-370.

80 Upton PAH, Roux CE, Noakes TD: Inadequate pre-season preparation of school-boy rugby players - A survey of players at 25 Cape Province high schools. S Afri Med J 1996;86:531-533.

81 Junge A, Rosch D, Peterson L: Prevention of soccer injuries: A prospective intervention study in youth amateur players. Am J Sports Med 2002;30:652-659.

82 Wedderkopp M, Kaltoft M, Lundgaard B, Rosendahl M, Froberg K: Prevention of injuries in young female players in European team handball. A prospective intervention study. Scand J Med Sci Sports 1999;9:41-47.

83 Bahr R, Lian O: A two-fold reduction in the incidence of acute ankle sprains in volleyball. Scand J Med Sci Sports 1997; 7:172-177.

84 Caraffa A, Cerulli G, Projetti M, Aisa G, Rizzo A: Prevention of anterior cruciate ligament injuries in soccer. A prospective controlled study of proprioceptive training. Knee Surg Sports Traumatol Arthrosc 1996;4:19-21.

85 Hewett TE, Lindenfeld TN, Riccobene JV, Noyes FR: The effect of neuromuscular training on the incidence of knee injury in female athletes. Am J Sports Med 1999;27:699-705.

86 Myklebust G, Engebretsen L, Braekken IH, Skjolberg A, Olsen O, Bahr R: Prevention of ACL injuries in female handball players: A prospective intervention study over 3 seasons. Clin J Sports Med 2003;13:71-78. 
87 Emery C, Cassidy D, Klassen T, Rosychuk R, Rowe B: The effectiveness of a proprioceptive balance-training program in healthy adolescents: A cluster randomized controlled trial (abstract). Am J Epidemiol 2004;159:S46.

88 Wedderkopp M, Kaltoft M, Holm R, Froberg K: Comparison of two intervention programmes in young female players in European handball - With and without ankle disc. Scand J Med Sci Sports 2003;13:371-375.

89 Marshall S, Mueller F, Kirby D, Yang J: Evaluation of safety balls and faceguards for prevention of injuries in youth baseball. JAMA 2003;289:568-574.

90 Emery CA, Meeuwisse WH: Risk factors for groin injuries in hockey. Med Sci Sports Exerc 2001;33:1423-1433.

91 MacKay M, Scanlan A, Olsen L: Sports and recreational injury prevention strategies: Systematic Review and Best Practices: Executive Summary. Vancouver, BC, BC Injury Research and Prevention Unit, 2001.

92 Janda DH, Maguire R, Mackesy D: Sliding injuries in college and professional baseball A prospective study comparing standard and break-away bases. Clin J Sport Med 1999;3:78-81.

93 Sendre RA, Keating TM, Hornak JE, Newitt PA: Use of the Hollywood Impact Base and standard stationary base to reduce sliding and base-running injuries in baseball and softball. Am J Sports Med 1994;22:450-453.

94 Sitler M, Ryan J, Wheeler B: The efficacy of a semi-rigid ankle stabilizer to reduce acute ankle injuries in basketball: a randomized clinical study at Westpoint. Am J Sports Med 1994;22: 454-461.

95 Benson BW, Rose MS, Meeuwisse WH: The impact of face shield use on concussions in ice hockey: A multivariate analysis. Br J Sports Med 2002;36(1):27-32.

96 Benson BW, Mohtadi NG, Rose MS, Meeuwisse WH: Head and neck injury among intercollegiate ice hockey players wearing full versus half face shields. JAMA 1999;282:2328-2332.

97 Meeuwisse WH: Full facial protection reduces injuries in elite young hockey players. Clin J Sport Med 2002;12:406.

98 Pashby T: Eye injuries in Canadian amateur hockey. Can J Ophthalmol 1985;20:2-4.

99 Torg JS, Vegso JJ, Sennett B: The National Football Head and Neck Injury Registry: 14 year report on cervical quadriplegia (1971-1984). Clin Sports Med 1987;6:61-72.

100 Roberts WO, Brust JD, Leonard B, Hebert BJ: Fair-play rules and injury reduction in ice hockey. Arch Pediatr Adolesc Med 1996;150:140-145.

101 Watson RC, Singer CD, Sproule JR: Checking from behind in ice hockey: A study of injury and penalty data in the Ontario University Athletic Association hockey league. Clin J Sport Med 1996;6:111.

102 Tropp H, Askling C, Gillquist J: Prevention of ankle sprains. Am J Sports Med 1985;13:259-262.

103 Hoffman M, Payne VG: The effects of proprioceptive ankle disk training on healthy subjects. J Orthop Sports Phys Ther 1995;21:90-94.

104 Holme E, Magnusson SP, Becher K, Bieler T, Aagaard P, Kjaer M: The effect of supervised rehabilitation on strength, postural sway, position sense and re-injury risk after acute ankle ligament sprain. Scand J Med Sci Sports 1999;9:104-109.

105 Emery CA, Cassidy D, Klassen T, Rosychuk R: The effectiveness of a proprioceptive balance training program in healthy adolescents. 6th World Conference on Injury Prevention and Control (abstracts), Montreal, Quebec, 2002.

106 Macnab A, Smith T, Gagnon F, Macnab M: Effect of helmet wear on the incidence of head/face and cervical spine injuries in young skiers and snowboarders. Inj Prev 2002;8:324-327.

107 Thompson D, Rivara F, Thompson RS: Effectiveness of bicycle safety helmets in preventing head injuries: A case-control study. JAMA 1996;276:1968-1973.

108 Wingfield K, Matheson GO, Meeuwisse WH: Preparticipation evaluation: An evidence-based review. Clin J Sport Med 2004;14:109-122.

109 Tursz A, Crost M: Sports related injuries in children. A study of their characteristics, frequency, and severity, with comparison to other types of accidental injury. Am J Sports Med 1986;14: 294-299.

110 Wright IC, Neptune RR, van den Bogert AJ, Nigg BM: The effects of ankle compliance and flexibility on ankle sprains. Med Sci Sports Exerc 2000;31:260-265. 
111 Thompson N, Halpern B, Curl W, Andrews J, Hunter S, McLeod W: High school football injuries: Evaluation. Am J Sports Med 1987;15:S97-S104.

112 Donner A, Klar N: Design and Analysis of Cluster Randomization Trials in Health Research. New York, Oxford University Press, 2000.

113 Rothman K, Greenland S: Modern Epidemiology, ed 2. Philadelphia, Lippincott-Raven Publishers, 1998.

Prof. C. A. Emery

Sport Medicine Centre, Faculty of Kinesiology

University of Calgary

2500 University Drive N.W.

Calgary, Alta., T2N 1N4 (Canada)

Tel. +1 403220 4608, Fax +1 403220 9489, E-Mail caemery@ucalgary.ca 